\title{
ATIVIDADE ANTIMICROBIANA DO EXTRATO HIDROALCÓOLICO DE FICUS CARICA E POLYGALA SPECTABILIS
}

(Antimicrobial activity of hydroalcoholic extracts of Ficus carica and Polygala spectabilis)

Lew Kan Sprenger, Elane Guerreiro Giese, Jeannie Nascimento dos Santos, Marcelo Beltrão Molento

${ }^{1}$ Correspondência: lew.sprenger@gmail.com

RESUMO: O objetivo foi avaliar a eficácia de diferentes formulações de fitoterápicos candidatos a antimicrobianos, produzidos a partir de folhas de caamembeca (Polygala spectabilis - EFC) e figo (Ficus carica - EFF). Os fitoterápicos foram produzidos com 30 dias de percolação a $4^{\circ} \mathrm{C}$ e liofilizados, sendo posteriormente utilizados para realizar a marcha fitoquímica, o teste de toxicidade e o ensaio antioxidante. $\mathrm{O}$ bioensaio de ação antibacteriana foi realizado frente a Clostridium perfringens, Escherichia coli, Pseudomonas aeruginosa e Staphylococcus aureus utilizando diluições em caldo com concentrações exponenciais $\left(20 \mu \mathrm{g} \mathrm{ml}^{-1}\right.$ a 2560 $\mu \mathrm{g} \cdot \mathrm{ml}^{-1}$ ) dos extratos. Nas análises fitoquímicas, foram evidenciados diversos compostos com propriedades antimicrobianas. A atividade antioxidante mensurada em $640 \mu \mathrm{g} / \mathrm{ml}$, em relação ao ácido ascórbico, do EFC foi de $68,4 \%$ ao passo que para o EFF foi de $89,9 \%$. O EFF teve eficácia, frente a todas as bactérias testadas, com uma concentração bactericida mínima (CBM) de 1280; 2560; 1280 e 320 $\mu \mathrm{g} / \mathrm{ml}$, para C. perfringens, E. coli, P. aeruginosa e S. aureus, respectivamente, todavia o EFC só agiu frente a $S$. aureus, com CBM de $2560 \mu \mathrm{g} / \mathrm{ml}$. Os resultados obtidos nos testes bioquímicos, juntamente com os encontrados nos testes in vitro, evidenciaram que o EFF é um candidato a antimicrobiano.

Palavras-chave: Controle alternativo, Fitoterapia, Resistência microbiana

ABSTRACT: The objective was to evaluate the antimicrobial effectiveness of different formulations of herbal candidates, produced from leafs of caamembeca (Polygala spectabilis - EFC) and common fig (Ficus carica - EFF). Extracts were produced with 30 days of percolation at $4^{\circ} \mathrm{C}$ and lyophilized; subsequently they were used to perform the phytochemical march, toxicity test and antioxidant test. The antibacterial bioassay was performed against Clostridium perfringens, Escherichia coli, Pseudomonas aeruginosa and Staphylococcus aureus using dilution with exponential concentrations $\left(20 \mu \mathrm{g} \cdot \mathrm{ml}^{-1}-2560 \mu \mathrm{g} \cdot \mathrm{ml}^{-1}\right)$ of the extracts. Several compounds with antimicrobial properties were determined in phytochemical analysis. The antioxidant activity measured at $640 \mathrm{ug} / \mathrm{ml}$, compared to the ascorbic acid was $68.4 \%$ for the EFC while for the EFF was $89.9 \%$. The EFF was efficacious in different concentrations, against all bacteria tested, with the minimum bacterial concentration (MBC) of 1280; 2560; 1280 e $320 \mu \mathrm{g} / \mathrm{ml}$, to C. perfringens, E. coli, $P$. aeruginosa e $S$. aureus, however the EFC only acted against $S$. aureus, with 2560 $\mathrm{ug} / \mathrm{ml} \mathrm{MBC}$. The results of the biochemical tests, along with those found in in vitro tests showed that the EFF may be considered as an antimicrobial candidate Key Words: Alternative methods, Herbal medicine, Microbial resistance 


\section{INTRODUÇÃO}

Durante 0 processo de civilização, as comunidades iniciaram a descoberta e cultivo de espécies vegetais que poderiam ser úteis na sua vida, como por exemplo as plantas medicinais (Leão et al., 2007). Mesmo com a evolução da indústria farmacêutica, existe atualmente problemas na assistência médica e na logística medicamentosa brasileira. Para contornar esta situação, medicamentos produzidos a base de extratos vegetais, vêm sendo utilizados com bons resultados, frente a diversas afecções infecciosas e parasitárias, causadas por nematódeos gastrintestinais, carrapatos, bactérias e fungos. Os fitoterápicos são de fácil obtenção, além de possuírem baixo custo e serem, geralmente, atóxicos no meio ambiente (Sprenger et al., 2015). O Brasil é considerado privilegiado quanto a exuberância desses compostos, pois abriga mais de um quarto da flora mundial conhecida (Sousa et al., 2013).

A Floresta Amazônica apresenta uma grande diversidade vegetal, com diversas plantas com propriedades farmacêuticas. Muito embora, o caamembeca (Polygala spectabilis) e o figo (Ficus carica) estejam entre as plantas mais populares e estudadas, sendo que ambas possuem atividades anti-helmíntica, anti-inflamatória, antioxidante e antitussígeno em humanos (Leão et al., 2007; Sousa et al., 2013), estudos na área veterinária ainda são necessários.

A situação de patógenos apresentando resistência frente aos antimicrobianos utilizados rotineiramente na clínica médica veterinária é alarmante. Entre as bactérias que apresentam mais relatos de falha no tratamento estão o Clostridium perfringens, Escherichia coli, Pseudomonas aeruginosa e Staphylococcus aureus (D'Lima et al.,
2012). Estas bactérias estão envolvidas em inúmeros processos infecciosos, de grau leve a grave, como em enfermidades do canal auditivo, cutâneas, gastrintestinais e respiratórias (Quinn et al., 2011).

Tendo em vista a crescente seleção de bactérias resistentes e a falta de opções medicamentosas para combater estes patógenos, o objetivo deste trabalho foi avaliar diferentes formulações de fitoterápicos, produzidos a partir de folhas de caamembeca e figo, contra $C$. perfringens, $E$. coli, $P$. aeruginosa e $S$. aureus.

\section{MATERIAL E MÉTODOS}

Folhas frescas de caamembeca ( $P$. spectabilis) e figo ( $F$. carica) foram coletados de produtores no mercado Ver-o-Peso, Belém, PA, no mês de julho de 2014. O material foi identificado por meio de chaves de identificação botânica (Henderson, 1995). Após a colheita, as folhas foram secas a sombra e em temperatura ambiente, sendo posteriormente trituradas em moinho de facas.

Para a produção do extrato hidro alcoólico utilizou-se um frasco de cor âmbar, no qual foram colocados, separadamente, $72 \mathrm{~g}$ de folhas de cada planta isoladamente com $720 \mathrm{ml}$ de álcool etílico $70 \%(\mathrm{v} / \mathrm{v})$. Em seguida, o conteúdo ficou 30 dias armazenado em refrigerador a $4^{\circ} \mathrm{C}$, sob agitação periódica.

Após essa etapa, realizou-se a filtração, com auxílio de uma bomba de vácuo em funil com papel filtro para um frasco tipo Kitasato. Após a obtenção dos extratos, os mesmos foram concentrados em evaporador rotatório, sob pressão reduzida à temperatura inferior a $30^{\circ} \mathrm{C}$ e posteriormente foram liofilizados. O rendimento obtido em relação as folhas de caamembeca foi de $4,98 \%$ e para as folhas de figo foi de $5,13 \%$. 
Os fitoterápicos foram diluídos em água destilada na concentração de $10 \mathrm{mg} / \mathrm{ml}$, para a realização da determinação dos seguintes metabólitos (Matos, 1997): fenóis, taninos, antocianinas, antocianidinas, flavonóides,

leucoantocianidinas, catequinas, alcalóides. A dosagem de fenóis totais foi realizada pelo teste de FolinCiocalteu (McDonald et al., 2001). As absorbâncias dos extratos foram comparadas ao padrão de ác. gálico (1 a $50 \mu \mathrm{g} / \mathrm{ml}$ ).

A atividade sequestrante do radical DPPH foi determinada de acordo com a metodologia de Blois (1958), com modificações. Em microtubos tipo Eppendorf foram colocados $300 \mu \mathrm{l}$ dos extratos em diferentes concentrações $(40-640 \mu \mathrm{g} / \mathrm{ml})$ junto a $100 \mu \mathrm{l}$ de solução etanólica de DPPH $(0,1 \mathrm{mM})$. Para o branco da amostra foi adicionado $100 \mu \mathrm{l}$ de etanol (EtOH) ao invés do DPPH, enquanto que no branco do método foi utilizado $300 \mu \mathrm{l} \mathrm{EtOH}$ no lugar das amostras.

A solução foi misturada em agitador e posteriormente se transferiu $200 \mu \mathrm{l}$ do preparado para uma placa de 96 poços. O preparado foi incubado no escuro, sob temperatura ambiente por 30 min. Decorrido esse tempo, a absorbância de cada solução foi mensurada em espectrofotômetro a 515 $\mathrm{nm}$. Para o cálculo do efeito foi usada a seguinte fórmula:

$\mathrm{AA}(\%)=\left(\mathrm{ABS}_{\text {controle }}-\left(\mathrm{ABS}_{\text {amostra }}\right.\right.$ ABSBRamostra)) x 100) / ABS controle

Onde, $A B S_{\text {controle é a absorbância }}$ do controle, ABS amostra é a absorbância das amostras incubadas com diferentes concentrações e ABSBRamostra é a absorbância do branco da amostra.

A atividade antioxidante dos extratos testados foi comparada com padrão do antioxidante comercial ácido ascórbico (vitamina $\mathrm{C}$ ), o qual foi preparado em etanol e utilizado nas mesmas concentrações dos extratos.

A atividade citotóxica dos extratos foi avaliada seguindo a metodologia adaptada de Meyer et al. (1982). Ovos do microcrustáceo foram colocados em aquário contendo sal marinho artificial $(38 \mathrm{~g} / \mathrm{L})$ sob aeração constante e temperatura controlada $\left(28^{\circ} \mathrm{C}\right)$. Após eclosão, foram transferidos dez metanáuplios para placas de 24 poços, contendo os extratos diluídos e sal marinho: DMSO (1\% v/v), em concentrações variando de 31,75 a $8000 \mu \mathrm{g} / \mathrm{ml}$. O controle positivo utilizouse sulfato de quinidina. Os testes foram produzidos em triplicata. Após $24 \mathrm{~h}$ de contato, realizou-se a contagem do número de larvas vivas. A partir desse valor foi calculada a $\mathrm{CL}_{50}$. O critério de toxicidade dos extratos foi estabelecido de acordo com Déciga-Campos et al. (2007), sendo valores $>1000 \mu \mathrm{g} / \mathrm{ml}$ (não tóxicos), $\geq 500$ a $\leq 1000 \mu \mathrm{g} / \mathrm{ml}$ (fracamente tóxico) e $<500 \mu \mathrm{g} / \mathrm{ml}$ (tóxicos).

Todos os microrganismos foram obtidos da American Type Culture Collection (ATCC), sendo dois Grampositivos: C. perfringens (ATCC 12919) e S. aureus (29213), e dois Gramnegativos: $E$. coli (ATCC 25922) e $P$. aeruginosa (ATCC 27853).

As bactérias foram inoculadas em ágar $\mathrm{BHI}$ e incubados a $37^{\circ} \mathrm{C}$ por $24 \mathrm{~h}$. Transcorrido o tempo, realizou-se 0 subcultivo, transferindo $50 \mu \mathrm{l}$ do inóculo inicial para $50 \mathrm{ml}$ de caldo MuellerHinton, o qual foi incubado a $37^{\circ} \mathrm{C}$ por $1 \mathrm{~h}$, produzindo leve turvação, com densidade de 0,5 na escala McFarland, equivalente a $1,5 \times 10^{6}$ UFC $\mathrm{ml}^{-1}$.

O teste de difusão em ágar foi feito seguindo a metodologia de Karaman et al., 2003. Para tal, com auxílio de swabs estéreis, o inócuo microbiano foi semeado na superfície de placa de Petri com ágar Muller-Hinton, com profundidade de $4 \mathrm{~mm}$. Discos de papel filtro (6 $\mathrm{mm}$ de diâmetro) foram 
impregnados com $10 \mu \mathrm{l}$ de extratos. Foi utilizado o método de diluição seriada, com um total de oito concentrações diferentes dos fitoterápicos $(20$ a $2.560 \mu \mathrm{g} / \mathrm{ml})$. Os discos foram dispostos com $30 \mathrm{~mm}$ de distância da parede e de outro inócuo, visando impedir a sobreposição das zonas de inibição. Os controles negativos foram preparados utilizando os mesmos solventes utilizados para dissolver os extratos. Para controle positivo foi utilizado ciprofoxacina $(0,4 \mathrm{mg} / \mathrm{ml})$ e gentamicina $(0,3 \mathrm{mg} / \mathrm{ml})$. As placas inoculadas foram incubadas a $37^{\circ} \mathrm{C}$ durante $24 \mathrm{~h}$. Cada ensaio feito neste experimento foi realizado em triplicata. A atividade antimicrobiana foi avaliada através da medição da zona de inibição de crescimento bacteriano formados ao redor dos discos. A concentração inibitória mínima (CIM) foi determinada como a menor concentração da amostra que resultou na inibição completa do crescimento visível na placa. A concentração bactericida mínima (CBM) foi definida como a menor concentração do extrato capaz de causar a morte de $99,9 \%$ do inócuo.

\section{RESULTADOS E DISCUSSÃO}

Em ambos os extratos, foi detectada a presença dos seguintes metabólitos: fenóis, flavonoides, taninos, esteróides, triterpenos, resinas, catequinas, saponinas e alcalóides. Ao passo que antocianinas e antocianidinas foram encontrados em quantidade mensurável apenas no herbal de $F$. carica. O teor de fenóis totais para os extratos de caamembeca e figo, foram respectivamente: $71,4 \mathrm{mg} \cdot \mathrm{g}^{-1}( \pm 1,887) \mathrm{e}$ $168,2 \mathrm{mg} \cdot \mathrm{g}^{-1}( \pm 2,035)$, semelhantes a literatura (Márquez Mendoza, 2011).

Os compostos fenólicos possuem uma gama de atividades biológicas, como antioxidante, antitumoral e, principalmente, antimicrobiana. Isto é explicado pela habilidade de interagir e formar complexos de macromoléculas, tais como polissacarídeos e proteínas bacterianas. $O$ efeito antimicrobiano dos taninos deve-se à inibição de enzimas, pela ação direta na membrana e pela competição por íons metálicos, essenciais ao metabolismo microbiano. Já para os esteróides, a ação ocorre devido à alteração do $\mathrm{pH}$ do meio e alquilação de proteínas importantes dos micro-organismos patogênicos. Saponinas, triterpenos e catequinas possuem relativa atividade bactericida, principalmente contra bactérias Grampositivas.

A atividade antioxidante, na concentração de $640 \mu \mathrm{g} / \mathrm{ml}$, em relação ao controle positivo, para o EFC foi de $68,4 \%$ enquanto para o EFF foi de $89,9 \%$. Estes resultados, principalmente o encontrado no EFF, são expressivos, uma vez que o ácido ascórbico possui uma das maiores atividades antioxidantes existentes na natureza. Os compostos antioxidantes, tais como fenóis e flavonóides, possuem funções como atividades anticancerígenas, antiinflamatórias e antimicrobianas (Texeira et al., 2013). Esta última ocorre devido a oxidação de elementos fundamentais da parede celular, principalmente os peptideoglicanos, formando poros, comprometendo a integridade da parede e tornando a bactéria susceptível a agentes externos. A degradação é menor frente a bactérias Gram-negativas devido a estrutura mais complexa e do maior teor de lipídeos da parede celular, que podem tornar os patógenos mais resistentes a agentes externos (Efstratiou et al., 2012).

O ensaio de letalidade com $A$. salina possui alta confiabilidade para testar a toxicidade de fitoterápicos, devido a sua resistência ambiental. Este teste apresenta fundamental importância, quando se pretende testar os produtos em testes in vivo (Sprenger et al., 2015). Os resultados da CL50 do 
EFC e EFF foram, respectivamente: 2.281 e $1.458 \mu \mathrm{g} / \mathrm{ml}$. Portanto, nenhum dos extratos demonstrou ser tóxico.

A atividade antimicrobiana dos fitoterápicos está apresentada na Tabela 1. Houve ação do extrato de figo frente a C. perfringens, $E$. coli, $P$. aeruginosa. e S. aureus. Quanto ao extrato de caamembeca ocorreu significativa atividade apenas frente ao S. aureus.

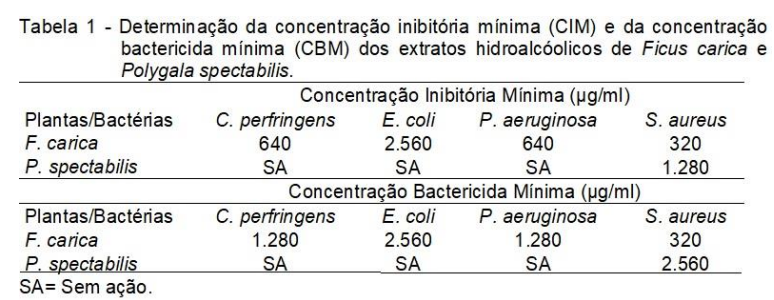

Segundo Carauta \& Diaz, (2002) extratos produzidos com folhas de plantas do gênero Ficus, como Ficus sycomorus, $F$. benghalensis, $F$. religiosa e $F$. racemosa, possuem atividade antimicrobiana frente a diferentes gêneros. Reschke et al. (2007) demonstraram ação de $F$. benjamina frente a diversas bactérias, entre elas $S$. aureus, $E$. coli e $P$. aeruginosa, com CBM de $2.048 \mathrm{mg} / \mathrm{ml}$ e CIM entre $512 \mathrm{a}$ $1.024 \mathrm{mg} / \mathrm{ml}$.

Jeong et al. (2009) pesquisaram o efeito de extrato metanólico de $F$. carica contra diversas bactérias e identificaram a ação do fitoterápico frente a $S$. aureus e $E$. coli, sendo que a CBM e CIM variaram entre 2,5 a 10 $\mathrm{mg} / \mathrm{ml}$. Al-Yousuf (2012) visualizaram a ação bactericida de extrato metanólico de $F$. carica perante E. coli, $P$. aeruginosa e $S$. aureus. Lee \& Cha (2010) também observaram o efeito do extrato metanólico de $F$. carica frente a $S$. aureus. Esta bactéria possui grande sensibilidade a antibióticos e substâncias com tal potencial, sendo usado como bioindicador para analisar essa propriedade.

A caamembeca é um vegetal
muito utilizado pela população amazônica, principalmente devido seu efeito anti-helmíntico, antidiarreico e expectorante (Leão et al., 2007). Porém, não há trabalhos científicos demonstrando suas propriedades antimicrobianas, sendo este a primeira pesquisa determinando seu espectro de atividade e baixo efeito tóxico.

No teste de Folin-Ciocalteu, foi observado pouco conteúdo de fenóis totais, classe de biomoléculas que possui ação antimicrobiana pronunciada. Uma maneira de aumentar a quantidade de compostos fenólicos, como flavonóides e antocianinas, e consequentemente melhorar a ação frente a bactérias seria a digestão fria em metanol das folhas.

As infecções causadas por bactérias resistentes ao tratamento com antibióticos convencionais são uma realidade mundial. Esta situação apresenta uma grande preocupação para a saúde pública e veterinária devido ao reduzido arsenal terapêutico disponível para tratamento em muitos casos (Quinn et al., 2011). O problema é maior quando ocorre desenvolvimento de resistência em bactérias zoonóticas, a exemplo dos patógenos utilizados no presente estudo, constituindo assim um maior risco para a saúde pública, pois podem afetar a eficácia do tratamento de infecções em humanos (D'Lima et al., 2012).

A pesquisa da atividade antimicrobiana da flora amazônica constitui uma alternativa viável para somar as formas alternativas de controle, sendo que este trabalho servirá como base para o desenvolvimento de novos fitoterápicos.

\section{CONCLUSÃO}

Os resultados obtidos indicam ser promissora a utilização do extrato hidro alcóolico de figo no controle das bactérias $C$. perfringens, $E$. coli, $P$. aeruginosa e $S$. aureus potencialmente patogênicas pesquisadas, uma vez que 
a concentração inibitória mínima e a concentração bactericida mínima foram iguais ou inferiores a $2560 \mu \mathrm{g} / \mathrm{ml}$. Todavia, novas formulações necessitam ser testada buscando maximizar a eficácia do produto.

\section{REFERÊNCIAS}

AL-YOUSUF, H.H.H. Antibacterial activity of Ficus carica L. extract against six bacterial strains. Internacional Journal of Drug Development and Research, v. 4, p. 307-310, 2012.

BLOIS, M.S. Antioxidant determinations by the use of a stable free radical. Nature, v. 181, p. 1199-1200, 1958. CARAUTA, J.P.P.; DIAZ, B.E. Figueiras no Brasil. Rio de Janeiro: UFRJ, 2002. 85p.

DÉCIGA-CAMPOS, M.; RIVERO-CRUZ, I.; ARRIAGA-ALBA, M.; CASTAÑEDACORRAL, G.; ANGELES-LÓPEZ, G.E.; NAVARRETE, A.; MATA, R. Acute toxicity and mutagenic activity of Mexican plants used in traditional medicine. Journal of Ethnopharmacology, v. 110, n. 2, p. 334-342, 2007.

D'LIMA, L.; FRIEDMAN, L.; WANG, L.; XU, P.; ANDERSON, M.; DEBABOV, D. No decrease in susceptibility to NVC422 in multiple-passage studies with methicillin-resistant Staphylococcus aureus, S. aureus, Pseudomonas aeruginosa, and Escherichia coli. Antimicrobiology. Agents and Chemicals, v. 56, n. 5, p. 2753-2755, 2012.

EFSTRATIOU, E.; HUSSAIN, A.I.; NIGAM, P.S. MOORE, J.E.; AYUB, M.A.; RAO, J.R. Antimicrobial activity of Calendula officinalis petal extracts against fungi, as well as Gram-negative and Gram-positive clinical pathogens. Complementary Therapies and Clinical Practices, v. 18, n. 3, p. 173-176, 2012.

HENDERSON, A. The palms of the Amazon. Oxford: University Press, 1995. 388p.
JEONG, M.R.; KIM, H.Y.; CHA, J.D. Antimicrobial activity of methanol extract from Ficus carica leaves against oral bacteria. Journal of Bacteriology and Virology, v. 39, n. 2, p. 97-102, 2009.

LEÃO, R.B.A.; FERREIRA, M.R.C.; JARDIM, M.A.G. Levantamento de plantas de uso terapêutico no município de Santa Bárbara do Pará, Estado do Pará, Brasil. Revista Brasileira de Farmacognosia, v. 88, n. 1, p. 21-25, 2007.

LEE, Y.S.; CHA, J.D. Synergistic antibacterial activity of fig (Ficus carica) leaves extract against clinical isolates of Methicillin-resistant Staphylococcus aureus. Korean Journal Microbiology and Biotechnology, v. 38, n. 4, 2010. KARAMAN, İ.; ŞAHIN, F.; GÜLLÜCE, M.; ÖGÜTÇÜ, H.; SENGÜL, M.; ADIGÜZEL, A. Antimicrobial activity of aqueous and methanol extracts of Juniperus oxycedrus L. Journal of Ethnopharmacology, v. 85, p. 231-235, 2003.

MATOS, F.J.A. Introdução à fitoquímica experimental. 2 ed. EUFC: Fortaleza, 1997. 141p.

MÁRQUEZ MENDOZA, G.D.C. Capacidad antioxidante y caracterización estructural de las antocianinas de los frutos rojos de Prunus domestica L., Ficus carica L. y Vitis vinifera L. cv" red globe" cultivados en Perú. 2011. 90f. Dissertação (Mestrado) - Facultad de Farmacia y Bioquímica, Universidad Nacional Mayor De San Marcos, Lima.

MCDONALD, S.; PRENZLER, P.; ANTOLOVICH, M.; ROBARDS, Q. Phenolic content and antioxidant activity of olive extracts. Food Chemical, v. 73, p. 73-84, 2001.

MEYER, B.N.; FERRIGNI, N.R.; PUTNAM, J.E.; JACOBSEN, L.B; NICHOLS, D.E.; MCLAUGHLIN, J.L. Brine shrimp: a convenient general bioassay for active plant constituents. Planta Medica, v. 45, n. 5, p. 31-34, 1982. 


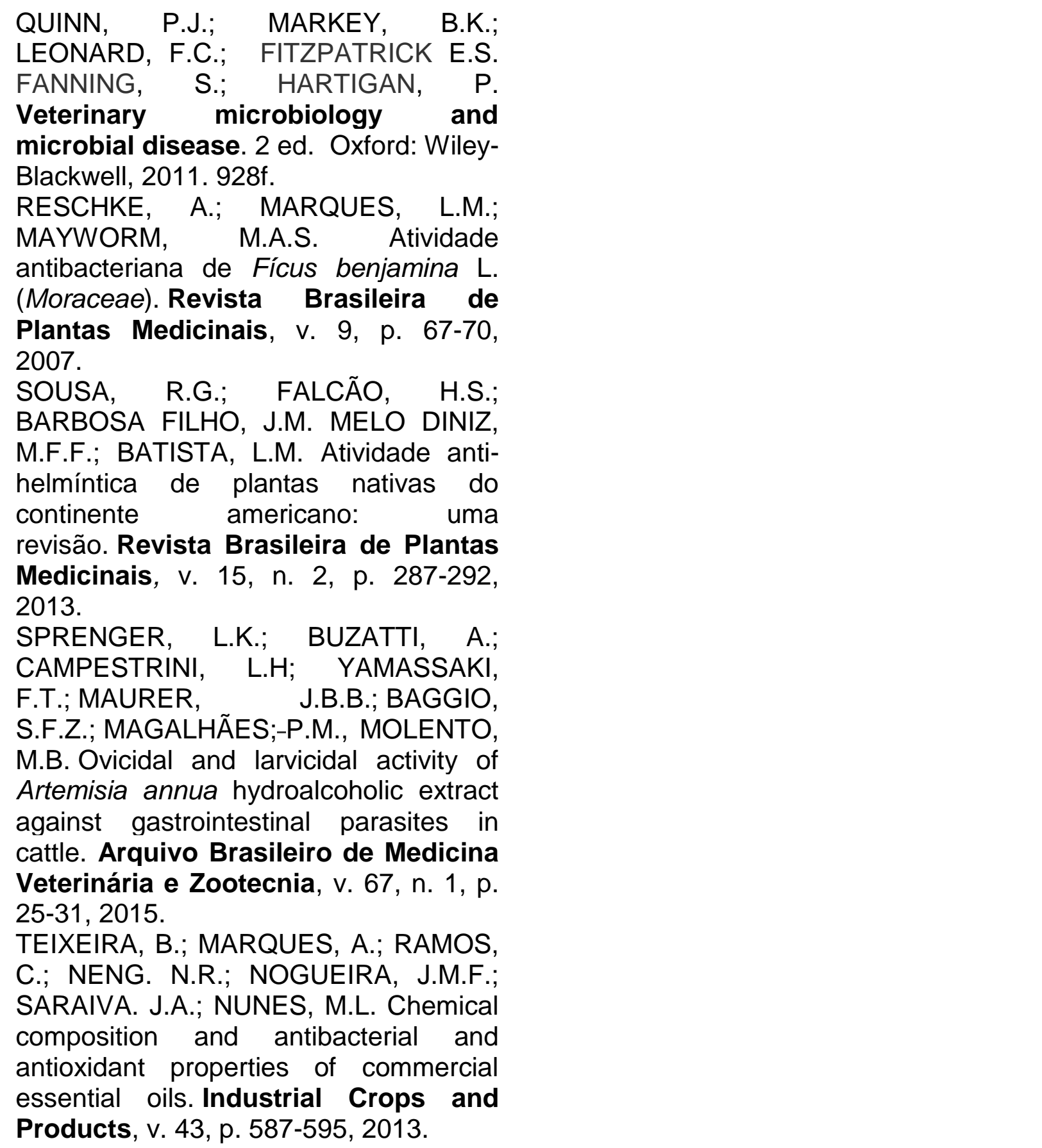

